\title{
THE DESC QUALITY PROGRAM FOR ELECTRONIC PARTS
}

\author{
Bradley A. Lantz \\ Robert E. Depp \\ Brian P. McNicholl \\ Defense Electronics Supply Center \\ 1507 Wilmington Pike \\ Dayton, OH 45444-5621
}

\begin{abstract}
This paper describes the Defense Electronics Supply Center's Quality Program and the results achieved. The primary objective of the program is to improve the quality of electronics parts being purchased. Each year the Center's quality program has become more and more successful in the deterrence of nonconforming electronic parts. A great deal of this success can be attributed to a strong receiving inspection test program, but equal attention is given to corrective actions and vendor ratings. The Vendor Rating System is used to influence the selection of a quality manufacturer and direct attention toward those producers who have difficulty supplying quality products.
\end{abstract}

A tremendous effort has been made to insert up-front quality requirements in over 25,000 plus procurements (per year). Timely, up-front actions preclude time consuming, costly post award work. DESC Product Quality has successfully shifted its attention from postaward to preaward functions which have resulted in tremendous returns on investment.

Emphasis is on the high payoff areas of weapon system parts and critical items with high demands. Resources are concentrated on both of these areas along with high dollar items. The intent is to maximize the beneficial effect of our Quality Program in order to stretch our declining resources. The belief is that the customers' (the Military Services) expectations are first and that they have the right to expect top quality products. Along with this right, DESC follows through with the belief that reliability is affected by Quality Assurance and varies directly with the emphasis placed on Quality Assurance programs.

This paper will discuss three main topics - the Qualification/Certification Program, the Product Quality Program and the DESC Test Program. All these programs are vital to DESC in improving the quality of electronic components for the Department of Defense (DoD).

\section{QUALIFICATION/CERTIFICATION}

DESC is the DoD Standardization Manager for Electronic Parts and acts as agent for the military departments in the preparation and development of military specifications and standards. DESC also administers the Qualification Program (QPLs/certification) and is the program manager for parts control. The QPL process is the first line of defense against electronic parts nonconformance. A QPL is a list of products meeting qualification requirements of government specifications. Qualification is the process by which products of manufacturers and distributors are examined and tested prior to listing on the QPL. DESC has approximately 186 QPLs with 1,250 manufacturers and 200 labs providing support. This work load equates to 520 facility audits per year with 3,000 test reports and 20,000 technical evaluations being performed.

The root purpose of the qualification program is to provide upfront evidence that a manufacturer has the ability to meet a specific military specification requirement at the time of examination. Program benefits are established sources, reduced leadtimes, and quality and reliability improvements. The steps for qualification are:

a. An audit of the manufacturing procedures, quality/reliability controls and testing capabilities, including failure analysis.

b. Review of the manufacturer's product assurance program for compliance with the military specification.

c. Steps for promotion of reliability growth.

d. Corrective actions consisting of defect isolation and acceptable corrective actions.

e. Verification that the corrections were effective.

f. Collect and periodically submit quality conformance data to the qualification program manager. 
There are also other restrictions placed on manufacturers which enhance DESC's up-front quality efforts, (i.e., products must be built on a DESC certified line). The product must be subjected to all screening tests and to all Group A, B, C, and D tests. The test report and samples must be submitted for review and approval.

A major component of the DESC qualification program is an audit of the manufacturer which leads to certification and consists of a detailed examination of the manufacturer's facility including:

a. Manufacturer's overall product assurance program.

b. Critical quality gates.

c. Actual product processing (fabrication, assembly).

d. Testing.

e. Environmental controls.

\section{f. Document control.}

Manufacturer certification is a prerequisite for participation in the JAN branding program for certain devices. This certification must be granted before the manufacturer is permitted to produce and supply JAN parts to the requirements of a military specification.

Although there may be more than one assembly/processing line at a manufacturer's plant, only the assembly/processing line that is audited is considered for manufacturer certification.

Passing qualification tests without manufacturer certification merely indicates that a manufacturer has demonstrated he can produce a product which meets the requirements of the specification at the time the product was manufactured. It is a one-time proof of capability on one lot of devices. By verifying process and plant controls and insuring adequate documentation of these controls, DESC's confidence is strengthened.

DESC not only verifies each manufacturer's documentation, but also checks to see if the manufacturer uses what appears to be good manufacturing practices. Technical questions are asked, actual work is witnessed and JAN electrical test programs are reviewed. This information is compared with the "standard of the industry."

Two of the most frequent problem areas in a manufacturer's plant are burn-in testing and electrical test programming. These are the areas that are critical because they can affect the reliability and success of DESC's quality program. As an example, one manufacturer had to throw away approximately 40 percent of his burn-in boards (numbering in the hundreds) because an audit revealed that the boards had the wrong resistor values, cold solder joints, defective resistors, defective sockets, etc. If this problem had not been found, the manufacturer might still be shipping parts that were not burned-in properly. Remember that the purpose of the burn-in and final electrical test is to find and eliminate defective and infant mortality parts.

Manufacturer certification has been granted to 18 manufacturers for 52 lines. The lines certified for these manufacturers consist of the following device types: digital, linear, memory and microprocessors.

In no way will manufacturer certification eliminate every one of DESC's quality problems. However, the intent is to have manufacturer certification reduce the variables that may cause problems. Because solid state technology is complex and very fluid, it is not possible to simply write a "cookbook" and expect it never to change. The objective is to maintain the discipline on documentation of what is being done and require compliance to the documentation. When major changes are made, the impact of the change must be evaluated so as not to introduce reliability problems. DESC's aim is to have manufacturer qualification/certification provide an excellent and effective means to verify and maintain process and plant controls and verify that the manufacturer is using good manufacturing practices. This verification is necessary so that the electronic devices that are furnished to DESC's customers perform as specified. DESC strives to supply parts that will enhance the reliability of its' customers communications and weapons systems.

\section{PRODUCT OUALITY}

The Product Quality function at DESC is responsible for Quality Assurance (QA) actions before and after contract award. Prior to 1988 , QA's role was little more than a complaint center where thousands of field complaints were answered monthly. No preventive measures were taken because the QA department functioned in a "reactive mode" instead of a proactive (preventive) mode. Field complaints were backlogged which adversely affected customer satisfaction and support.

After 1988, a change in philosophy was adopted in order to reduce time consuming, costly field complaints. The Preaward contract phase was made the top priority at DESC which consists of the following:

a. Purchase Request Reviews.

b. Development of Contract QA requirements.

c. Review of Missing Data Work Lists (MDWL's).

d. Development of Engineering Support Documents. 
Since 1988, Preaward actions have doubled in the Product Quality department, with the main emphasis placed on high dollar, critical weapon system components. Although Preaward actions cannot make an immediate impact on DESC's wide customer base, Product Quality has seen a large reduction in field complaints over the past 2 years. This reduction is directly related to up-front Preaward actions and the aggressive incoming inspection program in the DESC Test Facility.

In most QA programs (public or private sector), customer complaints must be addressed. At DESC, two basic types of complaints are received and handled by the QA department - Supply and/or Maintenance related. The supply complaints (known as Reports of Discrepancy), can range from a mismarked device to an overage or a shortage in quantity. The type of complaint that carries the highest impact to DESC and the user is referred to as the Product Quality Deficiency Report (PQDR). The PQDR is submitted by a user that is experiencing maintenance related problems. These problems can range from a simple malfunction to an inoperative major weapon system.

Product Quality's role in the PQDR process is to provide the user with an accurate and timely response to his or her complaint. Quality Assurance personnel have a difficult task in determining the exact cause of field failures, but have several tools available to assist them in their investigations. These include:

\section{a. A "world-class" state-of-the-art Test Facility} located at DESC.

b. Government representatives located in the manufacturers' facilities.

c. An extensive data base to track and monitor previous problems.

d. Application information submitted by the user.

Figure 1 shows the process flow of a typical field complaint submitted by the user. Each service utilizes a screening point which acts as the "hub" or control point for field complaints. The screening points maintain control over the complaints and are direct focal points with DESC. On the average, the Product Quality department at DESC receives and processes approximately 2,500 field complaints (PQDR's) annually with approximately 15 complaints resulting from inoperative weapon systems or grounded aircraft. These complaints are processed and investigated in a timely manner with an accurate response provided directly to the user.

\section{Incoming Process Flow} for Field Complaints

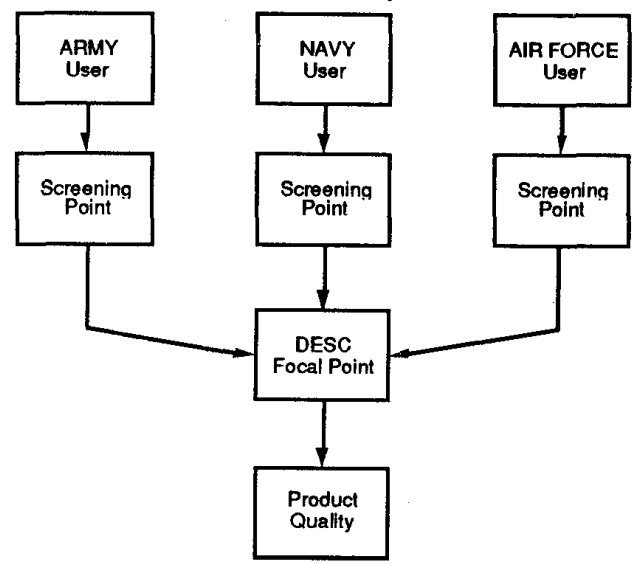

Figure 1.

\section{DESC Test Program}

Background. In January, 1977, DESC performed a study to determine if the center was receiving counterfeit discrete semiconductors from suppliers. Results indicated that $8.2 \%$ of the contracts contained counterfeit devices and an additional $20 \%$ failed to meet contractual quality requirements. As a result of recommendations to develop incoming inspection capabilities for discrete semiconductors, the DESC Test Facility was put into operation in late 1978.

At first, testing was limited to discrete semiconductors (FSC 5961). However, results indicated that in-house inspection capabilities should be expanded to cover the 18 primary supply classes managed by DESC. A new Test Facility was opened in March 1986 to accommodate this expansion.

Receiving Inspection has been the primary mission of the test program, but other programs have been developed and added as required.

Capabilities. The Test Facility is capable of performing electrical and mechanical testing on a wide variety of electronic spare parts and a large number of environmental, failure analysis and destructive physical analysis tests. Electronic parts tested range in complexity from state-of-the-art microprocessors to the most basic of resistors.

Programs. The DESC Test Facility utilizes five different programs to ensure that all parts are tested to the proper specifications and has the performance capabilities necessary to keep systems in operation. The five programs are listed in Table 1 along with a brief 
description of each and the number of test projects completed for each program.

An important new program was initiated and proved out in FY91. This program, named TRISTAR, is an effort to move the impact of the test program as far forward in the acquisition process as possible. The program involves working with the QARs in the contractors' facilities to ensure material offered for acceptance by the Government is conforming prior to it being accepted and sent to the supply depots. This concept has many benefits and cost savings for DESC. Some of these include:

a. Government knows product is conforming prior to acceptance.

b. Corrective action prior to shipment.

c. Eliminates holding costs of nonconforming products incurred by the Government.

d. Prevents shipping costs of defective material.

Other important information and statistics regarding accomplishments of the DESC Test facility in FY91 are contained in Table 2.

The DESC Test Facility provided direct support to Operation Desert Storm/Desert Shield during FY91. Over 200 test projects were performed on parts specifically purchased for ODS. In addition, rework was performed on urgently needed handsets for many ground based weapon systems used in the Gulf. Also, screening was performed on backordered stock with quality problems so that only conforming products were provided for use in the Gulf War.

DESC Quality Team Interfaces. The Test Facility plays a very important role in DESC's overall program to insure the quality of parts supplied to the military services. In many ways, the Test Facility acts as the eyes and ears of the Center's quality organizations by providing direct feedback to them regarding the quality of products being received. DESC's Engineering Standardization Directorate (E) has an integrated program in place consisting of Specification Management, Standardization and Parts Control, the Qualified Products List (QPL) or Qualified Manufacturers List (QML) with its attendant Manufacturer's Facility Audit Program. These programs interface with programs from other DESC organizations such as the Quality Vendor Program from the Directorate of Contracting and Production (P), Value Engineering Review from the Directorate of Technical Operations (S) and Assurance Programs from the Directorate of Quality Assurance (Q). All of the above functions are a concerted and cooperative effort with the goal of assuring part quality and reliability.
Table 1. 1991 DESC Test and Evaluation Programs

\begin{tabular}{|l|l|r|}
\hline PROGRAM & PURPOSE & PROJ \\
\hline $\begin{array}{l}\text { Receiving } \\
\text { Inspection }\end{array}$ & $\begin{array}{l}\text { Verify conformance of } \\
\text { new purchases to } \\
\text { contractual } \\
\text { requirements }\end{array}$ & 1,963 \\
\hline $\begin{array}{l}\text { Stock } \\
\text { Quality } \\
\text { Assurance }\end{array}$ & $\begin{array}{l}\text { Monitor quality of } \\
\text { depot stock }\end{array}$ & 442 \\
\hline $\begin{array}{l}\text { Support } \\
\text { Testing }\end{array}$ & $\begin{array}{l}\text { Support DESC, DLA, } \\
\text { and DoD electronic } \\
\text { component test and } \\
\text { evaluation needs }\end{array}$ & 259 \\
\hline $\begin{array}{l}\text { JAN Class } \\
\text { S DPA }\end{array}$ & $\begin{array}{l}\text { Perform Destructive } \\
\text { Physical Analysis on } \\
\text { high reliability Class } \\
\text { S)devices used in space } \\
\text { applications }\end{array}$ & 118 \\
\hline $\begin{array}{l}\text { Commercial } \\
\text { Test }\end{array}$ & $\begin{array}{l}\text { Supplement test and } \\
\text { evaluation capability }\end{array}$ & 102 \\
\hline Facilities & $\begin{array}{l}\text { Verify conformance of } \\
\text { products in Mfr's plant } \\
\text { prior to accept by } \\
\text { Government. }\end{array}$ & 8,892 \\
\hline TRISTAR & Grand Total \\
\hline
\end{tabular}

Table 2. Electrical Test Results

\begin{tabular}{||lr||}
\hline Receiving Inspection: \\
\hline \hline Parts Tested & 104,685 \\
Quantity Represented at Depots & $1,510,271$ \\
& \\
Parts Reject Rates & \\
Random Selection & $0.38 \%$ \\
Causative Selection & $0.75 \%$ \\
Overall & $0.69 \%$ \\
Lots Tested & 1,856 \\
Lots Rejected & $10.76 \%$ \\
\hline \hline Stock Quality Assurance: & \\
\hline \hline Parts Tested & 45,261 \\
Parts Reject Rate & $1.42 \%$ \\
\hline
\end{tabular}


All lots of material rejected in testing are referred to the DESC Product Quality Divisions for appropriate corrective actions. Some of these actions include returning the material to the contractor for reimbursement, investigation for fraud or other legal actions, process improvement in the production line, screening of stock at the depots, etc. Rejected military specification lots are referred to the DESC Qualifications Division for resolution and possible QPL/QML action. These actions are a positive feedback to the manufacturer which results in product improvements.

The Quality System at DESC has been instrumental in improving the quality of products being received. Part rejection rates in testing have decreased dramatically in the past ten years. The following graph (Figure 2) depicts this trend from FY82 through FY91. A regression analysis of the trend lines for both military specification and non-military specification items shows that the reject rates of both classes of items are steadily declining. Reject rates of non-military specification items have declined at a much higher rate, which would indicate that they are benefiting from the Quality program, in part, because there was much more room for improvement.

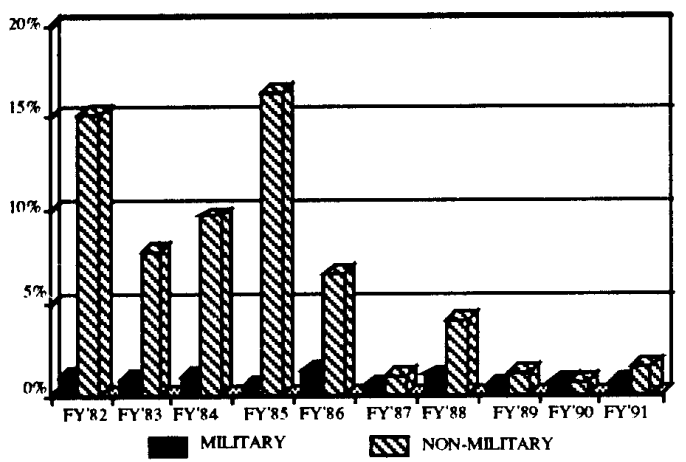

Figure 2. Receiving Inspection - 10 YR Part Failure Rate By MIL/NON-MIL

Summary. When all phases of the Quality system work concurrently the result is steadily improving product quality. When communication channels are open and an atmosphere of cooperation exists, large strides can be made. Figure 3 shows all of the integrated quality programs at DESC, which, when working together, lead to a quality product being supplied to the DoD.

\section{DESC's Quality Programs}

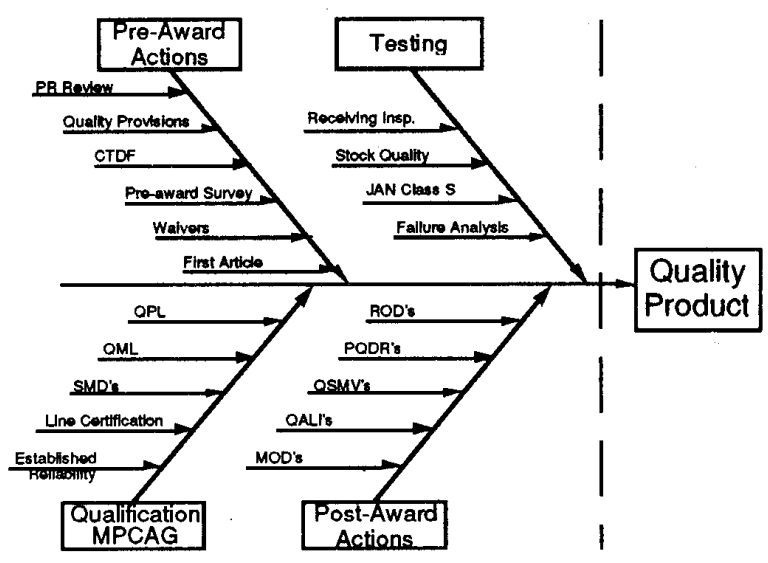

Figure 3

\section{BIOGRAPHY}

\section{Robert E. Depp DESC-Q}

Mr. Depp received his bachelor's degree in physics from Central State University, Wilberforce, Ohio, in 1969 , and was awarded the Master of Science Degree in Logistics Management, in 1973 from the School of Systems and Logistics, Air Force Institute of Technology. He is currently employed at the Defense Electronics Supply Center in Dayton, Ohio where he has served as a project engineer for electron tubes and as the Chief of the Electron Tubes and Parts Branch. He served as Chief of Parts Control and as Chief of the Assignee Activity Branch. He was Chief of the Qualifications Division prior to his current assignment as Director of Quality Assurance.

He served as the U.S. representative to NATO on the standardization of electronic parts. He also served as the DoD representative on the Institute of Electrical and Electronic Engineers (IEEE) Standards Review Committee. He was a member of the International Wire and Cable Symposium Committee. He is a member of the Society of Logistics Engineers (SOLE) and also belongs to the Institute of Electrical and Electronic Engineers (IEEE).

\section{Brian P. McNicholl DESC-QT}

Mr. McNicholl received a BS degree in Electrical Engineering from Michigan Technological University and a Masters Degree in Logistics Management from Central Michigan University. Since starting his career, he has been a specification writer in the Material and Parts area; a Standardization Program Manager in the 
Assignee Activity Branch; Chief of the Passive Devices Qualification Branch; and is presently Chief of the Test Division in the Directorate of Quality Assurance at DESC. Mr. McNicholl has acquired certifications from ASQC as both a quality and reliability engineer.

\section{Bradley A. Lantz}

DESC-QE

Mr. Lantz received his bachelor's degree in Electronic Engineering Technology from the University of Dayton in 1984, and a Masters Degree in Management Administration from Central Michigan University in 1991. Mr. Lantz is currently Chief of the Product Quality Division at the Defense Electronics Supply Center (DESC). His past assignments at DESC included Electronics Engineer in the Failure Analysis Branch and Test Engineer in the Passive Devices Test Branch. Prior to DESC, Mr. Lantz was employed as a Senior Product Quality Engineer for SGS-Thomson Microelectronics. His responsibilities included off-shore process control audits, inspections and coordination with Government agencies. 